\title{
Evidence for recovery of fear following immediate extinction in rats and humans
}

\author{
Daniela Schiller, ${ }^{1,2,3}$ Christopher K. Cain, ${ }^{2,3}$ Nina G. Curley, ${ }^{1}$ Jennifer S. Schwartz, ${ }^{1}$ \\ Sarah A. Stern, ${ }^{2}$ Joseph E. LeDoux, ${ }^{2}$ and Elizabeth A. Phelps ${ }^{1,2,4}$ \\ ${ }^{1}$ Psychology Department, New York University, New York, New York 10003, USA; ${ }^{2}$ Center for Neural Science, \\ New York University, New York, New York 10003, USA
}

\begin{abstract}
Fear responses can be eliminated through extinction, a procedure involving the presentation of fear-eliciting stimuli without aversive outcomes. Extinction is believed to be mediated by new inhibitory learning that acts to suppress fear expression without erasing the original memory trace. This hypothesis is supported mainly by behavioral data demonstrating that fear can recover following extinction. However, a recent report by Myers and coworkers suggests that extinction conducted immediately after fear learning may erase or prevent the consolidation of the fear memory trace. Since extinction is a major component of nearly all behavioral therapies for human fear disorders, this finding supports the notion that therapeutic intervention beginning very soon after a traumatic event will be more efficacious. Given the importance of this issue, and the controversy regarding immediate versus delayed therapeutic interventions, we examined two fear recovery phenomena in both rats and humans: spontaneous recovery (SR) and reinstatement. We found evidence for SR and reinstatement in both rats and humans even when extinction was conducted immediately after fear learning. Thus, our data do not support the hypothesis that immediate extinction erases the original memory trace, nor do they suggest that a close temporal proximity of therapeutic intervention to the traumatic event might be advantageous.
\end{abstract}

Fear conditioning is a widely studied laboratory paradigm for investigating psychological and neural mechanisms of emotional learning in animals, including humans (LaBar et al. 1998; Fendt and Fanselow 1999; LeDoux 2000; Davis and Whalen 2001; Maren and Quirk 2004; Phelps et al. 2004; LaBar and Phelps 2005; Olsson et al. 2005). In a typical experiment, a neutral conditional stimulus (CS), such as a tone or image, is paired in time with an aversive unconditional stimulus (US), often an electrical shock. After conditioning, the CS elicits a fear state consisting of behavioral, autonomic, and endocrine responses.

After conditioning, fear of the CS can be reduced or eliminated with an extinction procedure consisting of repeated presentations of the CS without the aversive US. Extinction is believed to induce new inhibitory learning that suppresses fear expression but leaves the original CS-US memory trace intact (for review, see Myers and Davis 2002). Evidence for this comes mainly from behavioral studies demonstrating that CS-elicited fear can return after extinction, an impossibility if extinction caused erasure of the original association. The most commonly cited behavioral phenomena supporting this inhibitory learning hypothesis are spontaneous recovery (SR), reinstatement, and renewal. In SR, CS fear re-emerges after extinction with the passage of time (Pavlov 1927; Baum 1988; Rescorla 2004). In reinstatement, unsignaled exposure to the US after extinction leads to context-dependent return of CS fear (Rescorla and Heth 1975; Bouton and Bolles 1979a; Westbrook et al. 2002). In renewal, CS fear returns when the CS is presented outside of the extinction context (Bouton and Bolles 1979b; Bouton and King 1983).

Despite this evidence for fear recovery, some reports suggest that extinction may induce partial or complete erasure of the CS-US memory trace. Molecular and physiological studies indi-

\footnotetext{
${ }^{3}$ These authors contributed equally to this work.

${ }^{4}$ Corresponding author.

E-mail liz.phelps@nyu.edu; fax (212) 995-4349.

Article is online at http://www.learnmem.org/cgi/doi/10.1101//m.909208.
}

cate that extinction may depend on phosphatase activity that reverses neural plasticity thought to mediate fear acquisition learning (Lin et al. 2003a,b). More recently, it has been suggested that extinction may induce erasure, inhibitory learning, or both, depending on the maturity of the fear acquisition memory. Myers et al. (2006), using rats in a fear-potentiated startle (FPS) paradigm, reported that extinction conducted 10 min after fear acquisition produced a loss of CS fear that did not show SR, reinstatement, or renewal. However, extinction conducted days after acquisition led to an initial loss of CS fear that did show recovery. Extinction conducted $1 \mathrm{~h}$ post-acquisition produced a loss of fear that only partially recovered. These findings led to the hypothesis that extinction conducted shortly after acquisition erases or prevents consolidation of initial fear learning, whereas extinction of well-consolidated fear learning generates a new inhibitory memory and leaves the original association intact. Extinction conducted between these two extremes, when the fear memory is partially consolidated, may lead to some erasure and some inhibitory learning. Other recent data also suggest that immediate and delayed extinction depend on different mechanisms (Cain et al. 2005).

Fear extinction research inspired the development of behavior therapy for human anxiety (Wolpe 1969; Rauch et al. 2006), and nearly all forms of behavioral therapy rely, at least partially, on extinction learning through exposure to fear-arousing stimuli in a safe context (Craske 1999). In addition, anxiety disorders may be characterized by deficiencies in extinction learning (Jacobs and Nadel 1985; Quirk and Gehlert 2003). Thus, findings from extinction research are widely believed to have clear and important implications for the treatment of human anxiety such as post-traumatic stress disorder.

One area of considerable controversy relates to the timing of therapeutic intervention following a traumatic experience. Some suggest that very early treatments such as "debriefings," which involve talking about trauma-associated cues in a safe setting, blunt the long-term impact of psychological trauma (Everly and 
and Mitchell 1999; Campfield and Hills 2001). However, others advocate delaying therapeutic intervention until stress related to the recent trauma has subsided (Bisson et al. 1997; McNally et al. 2003; Rothbaum and Davis 2003; Gray and Litz 2005; Maren and Chang 2006). Given that recovery of fear following successful extinction represents a major shortcoming of current therapeutic approaches (Jacobs and Nadel 1985), the possibility that immediate intervention prevents long-term fear recovery may outweigh concerns about exacerbating post-traumatic stress symptoms.

Following the Myers et al. (2006) finding, several laboratories began to explicitly test whether or not immediate extinction produces suppression of CS fear that does not recover. As a first follow up, Maren and Chang (2006) examined the efficacy of immediate extinction, which is necessary to demonstrate any recovery effects. They found that immediate extinction conducted in the context of acquisition is difficult to obtain in rats, which tempers the claim that immediate extinction can produce erasure. Recent human (Alvarez et al. 2007) and unpublished rat (A.M. Woods and M.E. Bouton, unpubl.) studies demonstrated intact renewal of CS fear after immediate extinction. In addition, there are existing studies that conducted extinction the same day as fear acquisition and reported recovery effects as measured by reinstatement, spontaneous recovery, and renewal (Quirk 2002; Phelps et al. 2004; LaBar and Phelps 2005; Milad et al. 2005, 2007; Kalisch et al. 2006; Dirikx et al. 2007). However, these latter studies were not designed to directly address the immediate extinction debate, allowing for parametric and procedural differences to account for the recovery effect. In the present studies, we directly examined the hypothesis that immediate extinction leads to fear suppression that does not recover with time (SR) or with unsignaled US exposure (reinstatement). Given the clinical implications of these phenomena, we chose to study both rat and human subjects. In addition, we measured two fear responses that differed from the Myers et al. (2006) study, freezing (in rats) and galvanic skin-conductance responses (in humans), to shed light on the generality of their finding. Contrary to the Myers et al. (2006) study, we found strong evidence for spontaneous recovery and reinstatement in both rats and humans following immediate extinction.

\section{Results}

\section{Humans}

\section{Reinstatement experiment}

Previous studies in our laboratory have developed a human reinstatement paradigm and shown that immediately extinguished conditioned fear can be recovered following reinstatement (LaBar and Phelps 2005). This effect was demonstrated using a single cue delay procedure as well as a delay discrimination procedure, both with a full reinforcement schedule, using skin-conductance responding (SCR) as the index of fear. This set of experiments showed that reinstatement in humans is context dependent and cue specific. That is, it does not generalize to other contexts or to nonpredictive cues. Another study also demonstrated the reinstatement effect after immediate extinction in humans using US expectancy and fear ratings (Hermans et al. 2005). In those experiments, however, the reinstatement and fear recovery tests were immediately preceded by extinction and acquisition (i.e., all stages were conducted in the same day). Myers at al. (2006) demonstrated fear erasure following immediate extinction using a different timeline, such that reinstatement was several days apart from acquisition followed by the recovery test $24 \mathrm{~h}$ later. This training protocol allows extinction learning to be fully consolidated prior to reinstatement, and in turn, reinstatement learning to be fully consolidated prior to the fear recovery test. Here, we developed a procedure comparable to that of Myers et al. (2006), in which the stages of extinction, reinstatement, and recovery test were separated by $24 \mathrm{~h}$, thus eliminating a time-dependent confound. We used reinstatement in a different context (Fig. 1) as a control for the reinstatement effect, which has been shown to be contextually mediated in both humans and rats (Bouton and Bolles 1979a; Bouton and King 1983, 1986; Bouton 1984; Bouton and Peck 1989; Frohardt et al. 2000; Westbrook et al. 2002; LaBar and Phelps 2005).

\section{Acquisition and extinction}

Figure 2 presents the mean $( \pm \mathrm{SEM})$ conditioned response as measured by SCR for both same and different context groups in the different experimental stages. During acquisition, responses to the CS were significantly greater than zero in both same $\left(t_{(15)}=5.67, P<0.001\right)$ and different context $\left(t_{(17)}=7.42\right.$; $P<0.001)$ groups. In each group, this conditioned responding significantly decreased during extinction (paired two-tailed $t$ tests; same, $t_{(15)}=3.53, P<0.01$; different, $\left.t_{(17)}=4.37, P<0.001\right)$. The responses in the last trial of extinction were not significantly different from zero (same, $t_{(15)}=2.08$; different, $t_{(17)}=1.67$ ). There was no significant difference between the same and different context groups in acquisition or extinction (independent two-tailed $t$-tests; acquisition, $t_{(32)}=1.08$; extinction, $\left.t_{(32)}=0.44\right)$. These results show that fear was successfully acquired and extinguished on day 1, in both same and different context groups at an equivalent level.

\section{Recovery test}

The results of the recovery test assessing reinstatement are presented in Figure 2 (between vertical solid lines). Recovery of immediately extinguished fear occurred in both groups regardless of the context of reinstatement. Specifically, there was a significant difference between the conditioned response in the last trial of extinction (before reinstatement) compared with the first trial of re-extinction (after reinstatement), in both same (paired twotailed $t$-test; $t_{(15)}=5.42, P<0.001$ ) and different context (paired two-tailed $t$-test; $\left.t_{(17)}=2.52 ; P<0.05\right)$ groups. However, the recovery was more robust when reinstatement took place in the
A

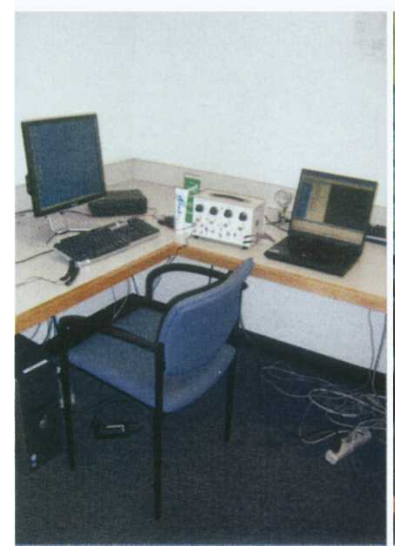

B

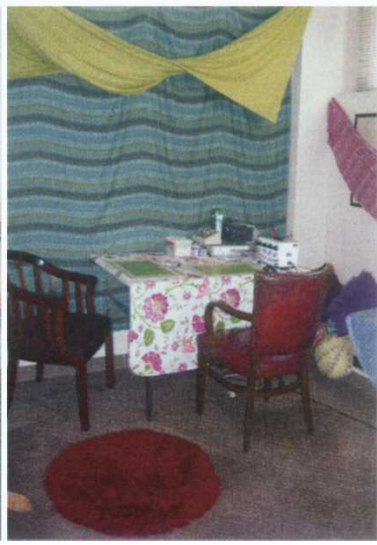

Figure 1. Illustrations of the experimental contexts in the reinstatement paradigm. (A) Context $\mathrm{A}$ was a typical laboratory setting in a windowless room with bare white walls containing an office desk and a chair. (B) Context B was located in another building and designed as a more domestic room with windows, colorful fabrics, a floor rug, pillows, wooden chairs, posters, several plants and flower arrangements, some scented candles, and classical music in the background. Also, a different experimenter, whom subjects did not meet in day 1 or 3 , guided the subjects in this context. 


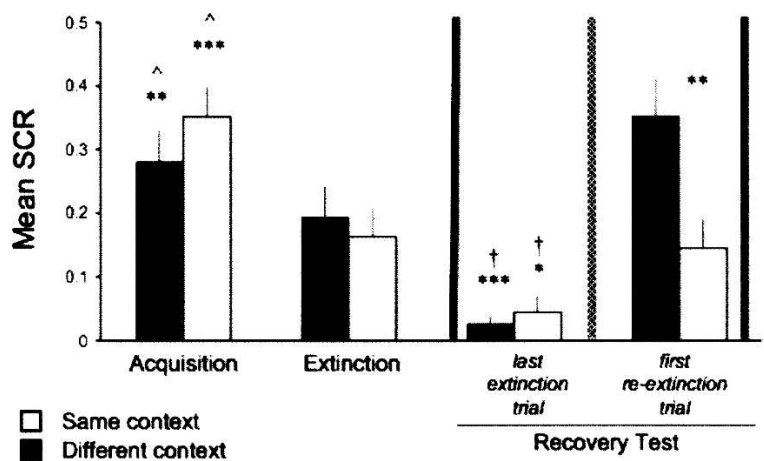

Figure 2. Reinstatement of CS fear following immediate extinction in humans. Mean ( \pm SEM) conditioned responses by context condition and experimental phase are presented. Both the same and different context groups showed acquisition of the conditioned fear that significantly decreased with extinction. The reinstatement phase occurred at the time point indicated by the vertical dashed line. The recovery test (between vertical solid lines), assessing reinstatement, compared the last trial of extinction (before reinstatement) and the first trial of re-extinction (after reinstatement). Although recovery of immediately extinguished fear occurred in both groups regardless of the context of reinstatement, the recovery was more robust when reinstatement took place in the same context as that of acquisition and extinction. This was supported by a more significant recovery in the same versus different context, as well as a significant difference in the first re-extinction response between the same and different context groups. Importantly, this was the only difference found between the two groups $\left({ }^{*} P<0.05 ;{ }^{* *} P<0.01 ;{ }^{* * *} P<0.001\right.$; $\wedge$ denotes comparison between acquisition and extinction within group; $\dagger$ denotes recovery test within group).

same context as acquisition and extinction. This was supported by the more significant recovery in the same versus different context $(P<0.001$ vs. $P<0.05$, respectively), as well as a significant difference in the first re-extinction response between the same and different context groups (independent two-tailed $t$-test; $\left.t_{(32)}=2.94, P<0.01\right)$. Importantly, this was the only difference found between the two groups. These results show that conditioned fear that is immediately extinguished in humans can be successfully recovered following reinstatement.

\section{Spontaneous recovery (SR) experiment}

To study SR in humans we used a partial reinforcement discrimination paradigm. In addition to examining the SR effect, we also sought to test whether this effect was cue specific or whether it would generalize to nonpredictive cues because of a general arousal effect. The use of a discrimination design, which is different from the single CS design used in the reinstatement experiment described above, allowed us to generalize the recovery effect across conditioning procedures, verifying that recovery following immediate extinction is not dependent on the particular conditioning parameters used.

\section{Acquisition and extinction}

The mean differential SCR (CS+ minus CS - ) during the different stages of the procedure is presented in Figure 3. The differential SCR was significantly greater than zero in acquisition $\left(t_{(13)}=2.50, P<0.05\right)$ and early extinction $\left(t_{(13)}=2.55, P<0.05\right)$. This differential responding significantly decreased from early to late extinction (paired two-tailed $t$-test; $t_{(13)}=2.19, P<0.05$ ) and by late extinction was no longer significantly different from zero $\left(t_{(13)}=1.26\right)$. These results show that conditioned fear was successfully acquired and extinguished on day 1 .

\section{Recovery test}

The results of the SR test are presented in Figure 3 (between vertical solid lines). This test compared the differential SCR to the first CS+ and CS - presented in re-extinction with the differential SCR and the last CS+ and CS - presented in extinction. The two phases of extinction and re-extinction were separated by $24 \mathrm{~h}$ (indicated by the vertical dashed line in Fig. 3). This comparison yielded a significant difference (paired two-tailed $t$-test; $\left.t_{(13)}=2.31 ; P<0.05\right)$. Moreover, the differential responding in the last trial of extinction was not significantly different from zero $\left(t_{(13)}=0.05\right)$ whereas the differential responding $24 \mathrm{~h}$ later was $\left(t_{(13)}=2.19, P<0.05\right)$. These results show that conditioned fear that is immediately extinguished in humans can spontaneously recover with the passage of time. Importantly, this effect was cue specific and did not generalize to nonpredictive cues. Thus, it cannot be attributed to a general arousal effect exhibited by elevated SCR, since such an effect would have not discriminated the predictive from the nonpredictive cue.

\section{Rats}

\section{Reinstatement experiment}

Reinstatement of conditioned fear was compared after immediate or delayed extinction with six experimental groups. There were three groups of rats in each condition: NE-R (no extinctionreinstatement), E-NR (extinction-no reinstatement), and E-R (extinction-reinstatement). The success of extinction was assessed at the post-extinction test. The return of conditioned fear after reinstatement shocks was assessed at the post-reinstatement test. Comparisons between no-extinction and extinction groups at the post-extinction test demonstrate long-term extinction memory in each condition. Comparisons between noreinstatement and reinstatement groups at the postreinstatement test demonstrate recovery of fear following unsignaled shocks in the test context. Comparisons between the postextinction test and the post-reinstatement test in the NE-R groups demonstrate summation of CS - and context fear following unsignaled shocks in the test context.

\section{Acquisition and extinction}

Acquisition of conditioned fear was identical in immediate and delayed extinction groups; freezing did not differ during the

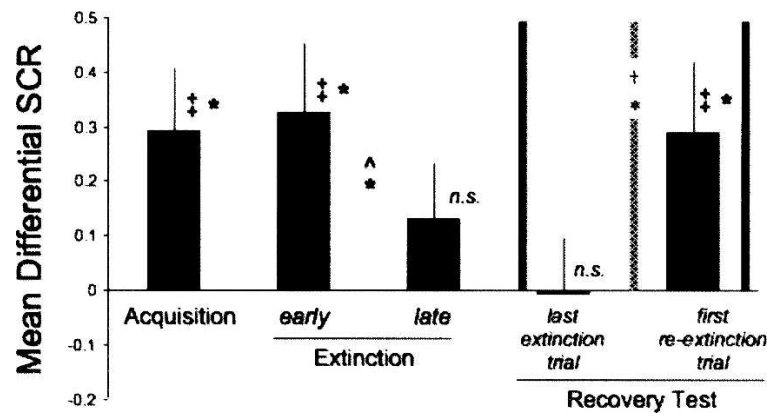

Figure 3. Spontaneous recovery of immediately extinguished fear in humans. Mean $( \pm S E)$ differential SCR $(C S+$ minus $C S-$ ) in each experimental phase is presented. A difference between responses to the CS+ compared to CS - was present during acquisition and immediate extinction but decreased by delayed extinction. The spontaneous recovery test (between vertical solid lines) compared the differential SCR with the first CS+ and CS - presented in re-extinction with the differential SCR to the last CS+ and CS - presented in extinction. Extinction and re-extinction were separated by $24 \mathrm{~h}$ (indicated by the vertical dashed line). As can be seen, the differential responding in the last trial of extinction was not significantly different from zero, whereas the differential responding $24 \mathrm{~h}$ later was. This increase in differential responding (recovery test) was statistically significant $\left({ }^{*} P<0.05\right.$; $\ddagger$ denotes comparison of the differential conditioned response to zero; $\wedge$ denotes comparison between early and late extinction; $\dagger$ denotes recovery test; n.s., not significantly different from zero). 
third conditioning trial of acquisition with data combined for both experiments $\left(t_{(58)}=0.6, P=0.56\right.$; Fig. 4). Note also that there were no differences between any of the individual groups in freezing during this third acquisition CS ( $P$-values $>0.05)$. The acquisition data for four rats were lost because of an error recording in one session, and these rats were excluded from the acquisition analysis but remained in the study for the rest of the experiment. Freezing prior to the first CS was near zero in both immediate and delayed extinction rats $\left(t_{(46)}=1.0, P=0.30\right)$. Within-session extinction differed between immediate and delayed extinction conditions; a two-way ANOVA revealed significant effects of group, trial, and the interaction (group: $F_{(1920)}=91.7, P<0.001$; time: $F_{(19,920)}=19.1, P<0.001$; group $\times$ time: $\left.F_{(19,920)}=2.8, P<0.001\right)$. Immediate extinction rats froze slightly less than delayed extinction rats at the outset of extinction training; however, freezing was not significantly different between the groups during the first extinction CS $(P>0.05)$. During the course of extinction, delayed extinction rats froze considerably more than immediate extinction rats, especially during CSs $3-9$ ( $P$ values $<0.05$ ). However, by the end of extinction training, rats in both groups showed near complete loss of CS-elicited freezing.

\section{Post-extinction and post-reinstatement tests}

Post-extinction and post-reinstatement tests were analyzed in separate two-way ANOVAs (group $\times$ test) for the immediate and delayed extinction conditions (Fig. 5). The two-way ANOVA in the immediate extinction condition revealed significant effects of group, test, and the interaction (group: $F_{(2,21)}=25.4$, $P<0.001$; test: $F_{(1,21)}=5.9, P<0.05$; group $\times$ test: $F_{(2,21)}=9.1$, $P<0.01)$. Long-term extinction was evident in the postextinction test; the E-NR and E-R groups froze significantly less than the NE-R group ( $P$-values $<0.01)$. Reinstatement of conditioned fear was also evident in the post-reinstatement test; rats in the E-R group froze significantly more during the test CSs than

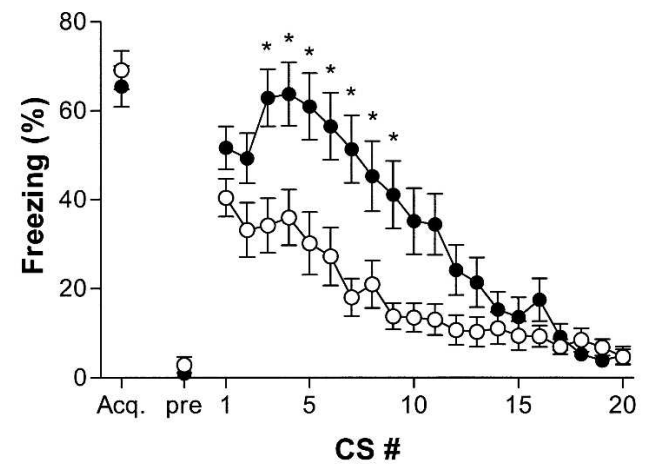

\section{$\multimap-$ Immediate Extinction $\rightarrow$ Delayed Extinction}

Figure 4. Rat fear acquisition and within-session extinction learning for all immediate extinction (open circles) and delayed extinction (closed circles) groups. Rats were presented with 20 nonreinforced CS presentations in a novel context immediately following fear acquisition (immediate extinction) or $3 \mathrm{~d}$ following fear acquisition (delayed extinction). Both groups showed equivalent levels of freezing during the third acquisition CS (acq.) and freezing was low prior to the first extinction CS (pre). Immediate extinction rats generally froze less and extinguished faster than delayed extinction rats. For the acquisition time point: $n=30$ rats/ group. For the extinction session time points: $n=24$ rats/group. Note that data were combined from the rat reinstatement experiment and spontaneous recovery experiment, since all animals within each group were treated identically through this phase. The data for four rats (two immediate extinction and two delayed extinction) were lost for the acquisition time point because of a recording error. ${ }^{*} P<0.05$ compared with immediate extinction.
A. Immediate Extinction

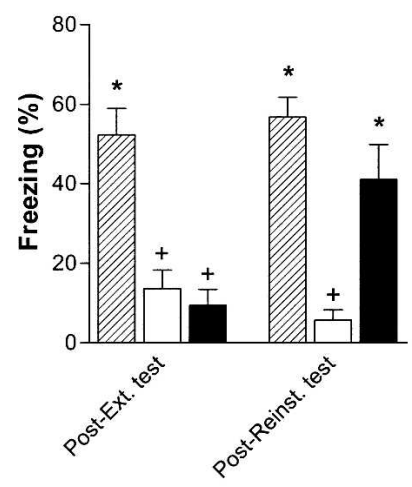

B. Delayed Extinction

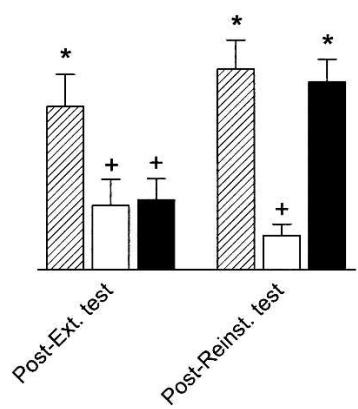

एü No Ext. - Reinst.

$\square$ Ext. - No Reinst.

Ext. - Reinst

Figure 5. Evidence for reinstatement of CS fear following immediate or delayed extinction in rats. $(A)$ Mean freezing during the post-extinction test (left, Post-Ext. test) and the post-reinstatement test (right, Post-Reinst. test) for all rats in the immediate extinction condition. (B) Mean freezing during the post-extinction test (left, Post-Ext. test) and the postreinstatement test (right, Post-Reinst. test) for all rats in the delayed extinction condition. Reinstatement of CS fear during the postreinstatement test was evident regardless of whether extinction occurred 12 min or $3 \mathrm{~d}$ following fear acquisition. Note also that summation of CS and context fear does not account for return of CS-elicited fear in the ext.-reinst. group; summation was minimal (compare CS-elicited freezing in the no-ext.-reinst. groups between the post-extinction test and the post-reinstatement test). (Hatched bars) No extinction-reinstatement; (open bars) extinction-no reinstatement; (solid bars) extinctionreinstatement. ${ }^{*} P<0.05$ vs. ext. - no-reinst. group, ${ }^{+} P<0.05$ vs. no-ext.reinst. group.

rats in the E-NR group $(P<0.05)$ and no differently from rats in the NE-R condition. Importantly, summation of CS fear and context fear (due to the unsignaled reinstating USs) was minimal; freezing in the NE-R group did not significantly differ between the post-extinction and post-reinstatement tests $\left(t_{(7)}=0.6\right.$, $P=0.56$ ). The two-way ANOVA for the delayed extinction condition revealed an identical pattern of results (group: $F_{(2,21)}=11.7, P<0.001$; test: $F_{(1,21)}=6.0, P<0.05$; group $\times$ test: $\left.F_{(2,21)}=6.4, P<0.01\right)$. Long-term extinction of freezing was evident $(P$ values $<0.05$ for extinction groups vs. the no-extinction group), CS freezing reinstated after unsignaled USs $(P<0.05$, E-NR vs. E-R), and summation of CS and context fear was minimal $\left(t_{(7)}=1.4, P=0.21\right.$, post-extinction vs. post-reinstatement test for NE-R group).

\section{Spontaneous recovery (SR) experiment}

Spontaneous recovery after immediate versus delayed extinction was examined with two groups of rats; immediate extinction rats received 20 nonreinforced CS presentations $\sim 12 \mathrm{~min}$ after the acquisition session ended, whereas delayed extinction rats received the same extinction three days after acquisition.

\section{Acquisition}

Freezing was assessed during the third acquisition CS, all 20 extinction CSs, and a single SR test CS. There was no difference between groups in freezing during the third acquisition CS, suggesting that fear conditioning was equivalent in the immediate and delayed extinction conditions $\left(t_{(14)}=0.2, P=0.89\right)$.

\section{Extinction}

As noted above, immediate extinction rats froze slightly less than delayed extinction rats during the first extinction CS and showed a more rapid decline in freezing during extinction training. How- 
ever, both groups showed similarly low freezing by the end of the extinction session.

\section{Recovery test}

Twenty-one days later, all rats were returned to Context B for a single SR test CS. SR was assessed by comparing freezing during the last extinction CS with freezing during the spontaneous recovery test CS with a two-way group (immediate vs. delayed extinction) $\times$ time (extinction end vs. spontaneous recovery test) ANOVA. There were no differences in freezing between the groups overall (group: $F_{(1,14)}=1.0, P=0.35$ ) or during either of these two CSs $(P$-values $>0.05)$. Spontaneous recovery of CSelicited freezing was evident in both groups (time: $F_{(1,14)}=0.9$, $P<0.01)$ and again this recovery did not differ between the groups (group $\times$ time: $F_{(1,14)}=0.3, P=0.63$ ).

\section{Discussion}

We tested the hypothesis that extinction conducted immediately after fear conditioning results in suppression of CS fear that does not recover with time (spontaneous recovery) or with unsignaled US presentations (reinstatement). We examined this hypothesis with both rats and human subjects, using different dependent measures of conditioned fear: freezing in rats and SCR in humans. We found strong evidence for recovery of fear following immediate extinction in all experiments. In the human immediate extinction experiments, allowing a 24-h delay between extinction and testing, or presenting the subjects with unsignaled USs, led to CS fear that was nearly equivalent to pre-extinction levels (Figs. 2, 3). The rat experiments allowed for a direct comparison between immediate and delayed extinction. We found no evidence that reinstatement or spontaneous recovery was weaker following immediate extinction. In both experiments, rats in the immediate extinction group froze at least as much as rats in the delayed-extinction group during the critical test (Figs. 5, 6). Thus, our data do not support the general hypothesis that immediate extinction erases or prevents the consolidation of recently acquired conditioned fear.

The rat experiments also allowed us to examine withinsession extinction learning rates with a considerable degree of statistical power, which is typically not possible in the FPS paradigm because the fear response is measured only after and not during the extinction session. Since rats in the immediate and delayed extinction conditions were treated identically through

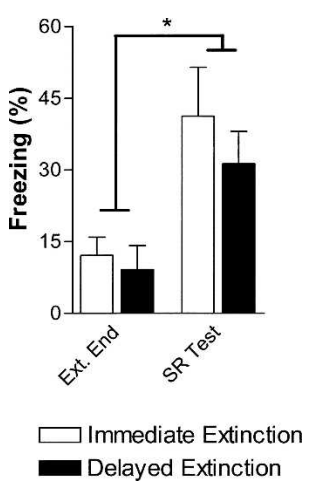

Figure 6. Evidence for spontaneous recovery following immediate or delayed extinction in rats. Mean freezing for immediate (open bars) and delayed extinction (solid bars) groups during the last extinction session CS (left) and the spontaneous recovery test session CS (right, $21 \mathrm{~d}$ later). Both groups showed significant spontaneous recovery of CS fear and the groups did not freeze differently at the end of extinction or during the SR test CS. ${ }^{*} P<0.05$ for time in a two-way group $\times$ time (Ext. End vs. SR Test) ANOVA. the end of the extinction training we combined the groups for analysis (Fig. 4). During extinction training, there was a nonsignificant trend toward higher freezing during the first extinction $\mathrm{CS}$ in the delayed extinction group and a large difference in freezing between the groups as training progressed. Immediate extinction rats froze less throughout the session and appeared to extinguish faster; however, it is likely that this reflects differences in performance rather than learning. Rats in the immediate and delayed groups froze the same during the third CS-US pairing of acquisition, suggesting that learning was equivalent in the two groups. And, as noted above, spontaneous recovery and reinstatement were equivalent in the immediate and delayed groups, a result that might not be expected if the immediate extinction rats had weaker initial learning or disrupted consolidation. Such a performance effect is not entirely surprising. For instance, Wagner's SOP and AESOP models (Wagner 1978, 1981; Wagner and Brandon 1989) predict that freezing will be disrupted at the outset of immediate, but not delayed, extinction even though rats in these groups may have equivalent CS-US associations. However, these models also predict that immediate extinction would be impaired relative to delayed extinction, which is not supported by our data. Clearly, this large behavioral effect requires further study. However, we are confident that animals in both conditions had strong CS-US associations from acquisition and strong fear extinction (see last extinction trial [Fig. 4] and the postextinction tests [Fig. 5]).

The present experiments were designed to assess whether the finding of Myers et al. (2006) would apply to a different behavioral measure in rats and would extend to humans. However, we were unable to demonstrate a difference in fear recovery between the immediate and delayed extinction conditions in rats. In humans, a number of studies have demonstrated fear recovery following immediate extinction, although these studies were not designed to directly address this question (Phelps et al. 2004; LaBar and Phelps 2005; Milad et al. 2005, 2007; Kalisch et al. 2006; Dirikx et al. 2007). Our findings in humans confirm and extend these existing data, directly demonstrating the return of the fear response due to spontaneous recovery and reinstatement following immediate extinction.

There are a number of differences between the study of Myers et al. (2006) and our own that could potentially account for the discrepancy. In the rat studies, we examined freezing rather than FPS as a measure of conditioned fear and used tone instead of light CSs. The procedure, stimuli, subjects, and dependent measure were all vastly different for the human studies, and any one of these differences could also account for the found discrepancy with the results of Myers et al. (2006). However, our findings are internally consistent (similar results in rats and humans) and are supported by several other lines of evidence. Studies previously demonstrated spontaneous recovery when extinction is conducted $1 \mathrm{~h}$ after fear acquisition (Quirk et al. 2000; Quirk 2002), consistent with our immediate extinction findings and partially at odds with those of Myers et al. (2006). An unpublished report showed intact renewal of CS fear when extinction was conducted $15 \mathrm{~min}$ after acquisition (A.M. Woods and M.E. Bouton, unpubl.). Alvarez et al. (2007) report intact renewal of CS fear after immediate extinction in humans, and this effect was demonstrated with two dependent measures (SCR and FPS). Reinstatement of CS fear after immediate extinction has also been indirectly implied by human studies that were not designed to examine this issue (Hermans et al. 2005; LaBar and Phelps 2005). Thus, the lack of fear recovery following immediate extinction may be a nuanced effect rather than a general property of extinction.

At first glance, our data may seem at odds with another study investigating immediate extinction. Maren and Chang 
(2006) report that recently acquired fear is resistant to extinction conducted 15 min later compared with extinction conducted 24 $\mathrm{h}$ later (using a conditioned fear paradigm in rats and measuring freezing). Importantly, they show that rats fail to learn extinction if CS-alone presentations begin immediately after acquisition and occur in the acquisition context. They did not explicitly examine fear recovery effects after extinction with this protocol because immediately extinguished rats do not learn extinction in the first place. They do show effective immediate extinction in a different context but do not report CS-fear recovery data. In our rat experiments, extinction took place in a different context than acquisition, and in this condition, immediate extinction is at least as effective as delayed extinction. There was no delayed extinction condition in our human experiments so we cannot comment on whether or not delayed extinction is more effective than immediate extinction when all phases are conducted in the same context. Nevertheless, immediate extinction, which was conducted in the acquisition context, was clearly effective. Our ability to manipulate fear in humans is limited for ethical reasons. It is likely that in the human experiments the levels of fear were much lower than those in the rat experiments reported by Maren and Chang (2006), and thus there was little contextual fear to impede extinction in the humans. Therefore, our data are not at odds with those reported by Maren and Chang (2006).

In addition to the basic finding that CS fear recovers after immediate extinction, our experiments provide support for two other hypotheses related to reinstatement of extinguished fear. Reinstatement is hypothesized to be context dependent (Bouton and Bolles 1979a; Bouton and Peck 1989) and to result from changes in the occasion-setting properties of the context, as opposed to summation of CS- and context-elicited fear (Bouton and King 1983). Our human reinstatement experiment examined reinstatement of CS fear in Context A after acquisition and extinction in Context A. We had two different reinstatement groups: one that received unsignaled USs in Context $\mathrm{A}$ and one that received unsignaled USs in Context $\mathrm{B}$. As predicted, reinstatement was context specific: Although subjects receiving the USs in either the same or different context as the final test showed a return of CS-elicited fear, this effect was significantly greater in the same context compared with the different context group. Importantly, that was the only difference between these two groups throughout the task (Fig. 2). The design of our rat reinstatement experiment allowed us to comment on the likelihood that summation of context- and CS-elicited fear accounts for reinstatement. Our no-extinction-reinstatement control groups received the same unsignaled US presentations in the extinction/ test context but were never extinguished. Comparing freezing between the post-extinction and post-reinstatement tests for these groups (Fig. 5) reveals that summation was minimal and cannot account for the robust reinstatement effect observed for the extinction-reinstatement group. Thus, these findings support the notion that reinstatement is context dependent and results from a process other than summation of CS and context fear.

It should be noted that in our human experiments we cannot be sure that immediate extinction had no detrimental effects on conditioning consolidation. Although we found in both reinstatement and spontaneous recovery experiments that the extinguished fear responses recovered to the same levels of conditioning (Figs. 2, 3), it is possible that a no-extinction group would have exhibited higher fear levels during fear recall because of an incubation effect (Eysenck 1968). However, a previous renewal study in humans (Milad et al. 2005) found that fear was recovered in an immediate extinction group to similar levels exhibited by a no-extinction group during the fear recall phase. These results indicate that immediate extinction did not interfere with conditioning consolidation, and the fear memory remained intact. Moreover, these results provide no evidence for an incubation effect in humans. In any event, the robust recovery rates we observed in our human experiments strongly argue against the erasure of fear suggested by Myers et al. (2006).

The results of spontaneous recovery in humans allowed us to rule out the possibility that the recovery occurred because of a general arousal effect. Such general elevation in SCR baseline would affect both CS+ and CS - responses indiscriminately. In contrast, we could observe significantly greater responding to the $\mathrm{CS}+$ versus the CS - levels upon return to the experimental context, $24 \mathrm{~h}$ after extinction. These results confirm the cue specificity of the spontaneous recovery effect, which is restricted to the CS alone.

Findings from fear extinction research have important implications for the treatment of pathological fear in humans for two related reasons. First, a critical component of nearly all cognitive-behavior therapies for fear disorders is fear extinction (Wolpe 1969; Craske 1999; Rauch et al. 2006). Thus, findings from extinction studies are likely to directly translate to better treatments for anxious patients. Second, fear disorders may be characterized by impairments in the ability to extinguish learned fear (Quirk and Gehlert 2003). Given this, findings from extinction studies may aid in targeting specific neural and psychological processes that are dysfunctional in pathological fear.

An area of considerable controversy regarding cognitivebehavioral therapy following severe trauma is the relative efficacy of immediate versus delayed interventions. Some believe that very early interventions, such as debriefings in a safe setting, aid in the long-term treatment of anxiety perhaps by blunting the traumatic memory or by preventing fear recovery following successful treatment (Everly and Mitchell 1999; Campfield and Hills 2001). However, the available data is mixed regarding the hypothesized benefit of early intervention. Indeed, some have argued that very early interventions exacerbate long-term fear by adding to the stress of the traumatic experience (Bisson et al. 1997; McNally et al. 2003; Rothbaum and Davis 2003; Gray and Litz 2005). If solid evidence existed that immediate extinction produced nonrecovering fear suppression, one could argue that early therapeutic interventions were warranted even if that meant adding to the patient's immediate level of discomfort. The jury is still out on this important debate, but our data indicate that immediate extinction does not prevent recovery of CS fear in rats and humans and suggest that cognitive-behavior treatments immediately following severe trauma may not be especially advantageous. Immediate and delayed extinction may, however, operate through different neural or molecular mechanisms (Cain et al. 2005), and future studies will be needed to examine the relative efficacy of pharmacological agents on these two processes.

\section{Materials and Methods}

\section{Humans}

\section{Reinstatement Experiment}

\section{Subjects}

Forty participants (18 to $27 \mathrm{yr}$ of age) were recruited through posted advertisements. Subjects were excluded from the experiment if on day 1 they showed no measurable SCR response (below minimal response criteria), failure to acquire the conditioned response (mean response of last four acquisition trials was not significantly different from zero), or failure to extinguish the fear response (mean response of last four extinction trials was not significantly different from mean late acquisition response). We employed these criteria because we could not assess fear recovery 
without a reliable SCR measure and without showing that the conditioned response was successfully acquired and extinguished. These exclusion criteria are widely accepted in the conditioning and extinction literature (Phelps et al. 2004; Milad et al. 2005; Olsson et al. 2005; Kalisch et al. 2006). The final analysis included 34 participants (18 females). The experiment was approved by the University Committee on Activities Involving Human Subjects. All subjects gave informed consent and were paid for their participation.

\section{Reinstatement procedure}

A 100\% reinforcement paradigm was used. The CS was a fractal image, and the US was a mild shock to the wrist. Two different fractal images were used and counterbalanced across subjects. All CSs in acquisition and extinction were presented for 6 sec with a variable 10- to 12 -sec inter-trial interval (ITI). Subjects were instructed to pay attention to the screen and notice whether there is a relationship between the presentation of the images and the shock. There were four stages to the study: acquisition, extinction, reinstatement, and re-extinction. The stages were completed over $3 \mathrm{~d}$ as follows: Day 1-Acquisition and extinction. During acquisition, there were four habituation trials and then eight presentations of the CS that co-terminated with the US. Extinction immediately followed acquisition (after the 10- to 12-sec ITI) with 16 nonreinforced presentations of the CS. Day 2-Reinstatement. Twenty-four hours later, subjects received four presentations of the US, with a 50-sec ITI. Subjects were randomly allocated into one of two groups. One group $(n=16)$ received the US presentations in the same room as day 1 (context A; Fig. 1A), while viewing the solid background color of the CS but not the CS itself. The other group $(n=18)$ received the presentations of the US in a different room (context B; Fig. 1B), located in another building and guided by a different experimenter, while viewing a different patterned background. Day 3-Re-extinction. Twentyfour hours later, all subjects returned to the same room that was used on day 1 (context A) and again underwent extinction, consisting of 20 nonreinforced presentations of the CS.

Psychophysiological stimulation and assessment

Mild shocks were delivered through a stimulating bar electrode attached with a Velcro strap to the right inner wrist. A Grass Medical Instruments stimulator charged by a stabilized current was used. Subjects determined the level of the shock themselves, beginning at a very mild level of shock $(10 \mathrm{~V})$ and gradually increasing the level until the shock reached the maximum level that they determined was "uncomfortable, but not painful" (the maximum level was $50 \mathrm{~V}$ ). All shocks were given for $200 \mathrm{msec}$, with a current of 50 pulses per second. Skin conductance was assessed using two $\mathrm{Ag}-\mathrm{AgCl}$ electrodes, which were connected to a BioPac Systems skin-conductance module. The electrodes were attached to the first and second fingers of the left hand, between the first and second phalanges.

SCR waveforms were analyzed offline, using AcqKnowledge 3.9 software (BIOPAC Systems Inc.). SCR amplitudes to the CS and US were the dependent measures of conditioned and unconditioned responses, respectively. The level of SCR response was determined by taking the base to peak difference for the first largest waveform (in microsiemens, $\mu$ s) in the 0.5 - to 4.5 -sec window following stimulus onset. The minimal response criterion was $0.02 \mu \mathrm{s}$. The raw SCR scores were square root transformed to normalize distributions. These normalized scores were scaled according to each subject's unconditioned response by dividing each response by the mean square-root-transformed US response. This additional step allowed us to account for individual differences in SCR and to compute a relative measure of conditioned response linked to each participant's unconditioned response (Olsson et al. 2005).

\section{Statistical analysis}

Trials were averaged into blocks representing each experimental phase (i.e., acquisition, extinction, and re-extinction). To test for the recovery of fear following reinstatement, data from the first re-extinction trial was compared with that of the last extinction trial (Rescorla and Heth 1975). An alpha level of 0.05 was set for all statistical comparisons.

\section{Spontaneous recovery experiment}

\section{Subjects}

Seventeen participants ( 18 to $28 \mathrm{yr}$ of age) were recruited through posted advertisements. Subjects were excluded from the experiment if on day 1 they showed no measurable SCR response, failure to acquire the conditioned response (no significant mean differential responding to CS+ compared with CS - in last four trials of acquisition), or failure to extinguish the fear response (a significant mean differential responding to CS+ compared with CS - in last four trials of extinction). The final analysis included 14 participants (seven females). The experiment was approved by the University Committee on Activities Involving Human Subjects. All subjects gave informed consent and were paid for their participation.

\section{Spontaneous recovery paradigm}

A simple discrimination, partial reinforcement paradigm was used. The CSs were two different colored snake images (red and four yellow), and the US was a mild shock to the wrist. One of the snake images was designated as the $\mathrm{CS}_{+}$, and paired with the shock on $33 \%$ of the trials, while the other was never paired with the shock $(\mathrm{CS}-)$. We used negatively valenced CSs to enhance overall emotional reactivity (Morris et al. 1998; Critchley et al. 2002; Ohman 2005; Kalisch et al. 2006). Each stimulus served as both CS+ and CS - counterbalanced across subjects. The CSs for acquisition and extinction were presented for 4 sec each with a 12 -sec ITI. Subjects were instructed to pay attention to the screen and notice whether there is a relationship between the presentation of the images and the shock. There were three stages to this paradigm: acquisition, extinction, and re-extinction. The stages were completed over $2 \mathrm{~d}$ as follows: Day 1-Acquisition and extinction. Acquisition consisted of nonreinforced presentations of the CS+ and CS - (12 each) intertwined with an additional six presentations of the CS+ that co-terminated with the US. Extinction immediately followed acquisition after the 12-sec ITI, with nonreinforced presentations of the CS+ and CS - (eight each). Day 2-Re-extinction. Twenty-four hours later, subjects returned to the same room that was used on day 1 and again underwent extinction, consisting of nonreinforced presentations of the CS+ and $\mathrm{CS}-(12 \mathrm{each})$.

\section{Psychophysiological stimulation and assessment}

These were the same as reinstatement paradigm (see above).

\section{Statistical analysis}

SCR following the US was analyzed to assess unconditioned responding, but only trials that did not coterminate with the US were analyzed to measure fear acquisition. The conditioned fear response was assessed as the differential SCR, that is, the SCR to the $\mathrm{CS}+$ minus the SCR to the $\mathrm{CS}-$. Trials were averaged into blocks representing the experimental phases. The use of a partial reinforcement procedure allowed for a slow extinction, since extinction occurs rapidly in humans with $100 \%$ reinforcement (LaBar et al. 1998; Phelps et al. 2004). Thus, the trials of the extinction phase were divided into first half and second half (early and late extinction) to identify a gradual change in responsivity as extinction progresses. To test for the recovery of fear due to passage of time (spontaneous recovery), the differential SCR to the first CS+ and CS - presented in re-extinction was compared with the differential SCR to the last CS+ and CS - presented in extinction. An alpha level of 0.05 was set for all statistical comparisons.

\section{Rats}

\section{Reinstatement Experiment}

Subjects

All experiments were conducted on naïve 300-350 g male SpragueDawley rats (Hilltop Lab Animals, Inc.) and were approved by NYU's Animal Care and Use Committee. Rats were main- 
tained on a 12:12 light/dark schedule and allowed free access to food and water. All testing was conducted during the light phase in illuminated testing rooms.

\section{Apparatus}

Two contexts (A and B) were used for all behavioral testing. Context A consisted of four standard fear-conditioning chambers (Model E10-10, Coulbourn Instruments). Chambers were constructed of aluminum and Plexiglas walls with stainless steel grid flooring that was attached to a shock generator (Model H13-15; Coulbourn Instruments). Context B consisted of four separate conditioning chambers (ENV-001; MedAssociates, Inc.) located in a different room. Context B chambers also had stainless steel grid flooring attached to scrambled shock generators (Models ENV410B and ENV412). Chambers were enclosed within sound attenuating cubicles. Chambers differed in shape $(\mathrm{L} \times \mathrm{W} \times \mathrm{H}$; A: $28.5 \mathrm{~cm} \times 26 \mathrm{~cm} \times 28.5 \mathrm{~cm} ;$ B: $24.5 \mathrm{~cm} \times 30 \mathrm{~cm} \times 21 \mathrm{~cm}$ ), lighting (A: dim house light; B: house light plus two bright cue lights always on), odor (A: no odor; B: peppermint soap in floor pan), and flooring (A: $5-\mathrm{mm}$ diameter rods spaced $1.5 \mathrm{~cm}$ apart; B: 4-mm diameter rods spaced $1.6 \mathrm{~cm}$ apart). Individual video cameras were mounted in the ceiling of each chamber and connected via a quad processor to a standard VCR and monitor for videotaping and scoring of freezing. Delivery of stimuli was controlled with Graphic State 2 Software (Coulbourn Instruments) in Context A and MedPC Software in Context B.

\section{Procedure}

The reinstatement experiment consisted of five phases: acquisition, extinction, post-extinction test, reinstatement, and postreinstatement test. Acquisition took place in Context $\mathrm{A}$, and all other phases took place in Context B. Acquisition consisted of three CS-US pairings (acclimation period $=5 \mathrm{~min}$; ITI $=5 \mathrm{~min}$; post-conditioning period $=5 \mathrm{~min})$. The $\mathrm{CS}$ was a pure tone $(30$ sec, $80 \mathrm{~dB}, 5 \mathrm{kHz})$ and the US was a scrambled footshock $(0.7 \mathrm{~mA}$, $1 \mathrm{sec}$ ) that coterminated with the CS. Extinction consisted of 20 massed presentations of the CS alone (acclimation period $=2 \mathrm{~min}$; ITI = $5 \mathrm{sec}$; post-extinction period $=2 \mathrm{~min})$. Reinstatement consisted of three unsignaled US presentations (acclimation period $=$ $5 \mathrm{~min}$; ITI $=2 \mathrm{~min}$; post-shock period $=5 \mathrm{~min}$ ). The postextinction and post-reinstatement tests were identical and consisted of five CS alone presentations (acclimation period $=2 \mathrm{~min}$; ITI $=3 \mathrm{~min}$; post-test period $=2 \mathrm{~min}$ ). Two extinction conditions were examined: immediate extinction and delayed extinction. Within each condition, three separate groups of rats were run ( $n=8$ rats/group): (1) no-extinction-reinstatement (NE-R); (2) extinction-no-reinstatement (E-NR); and (3) extinctionreinstatement (E-R). Thus, six groups of rats were run beginning on the same day. All rats received the same acquisition session on day 1 . Immediate extinction rats were removed from the acquisition chambers in Context A and immediately moved to the Context B chambers. The two extinction groups then began receiving CS presentations in Context $\mathrm{B} \sim 12-15$ min after the final acquisition trial. The no-extinction group just remained in the Context B chambers for an equivalent amount of time. After the extinction session all rats were returned to their home cages in the colony room. All delayed extinction rats were returned to their home cages in the colony room after acquisition and remained there for $3 \mathrm{~d}$. On day 4, the delayed extinction groups were placed in Context B for their extinction session, which was the same as the immediate extinction groups (20 CS presentations for extinction groups, no CS presentations for the noextinction group). On day 5 , all rats were returned to Context $\mathrm{B}$ to probe CS-elicited fear during the post-extinction test. On day 6 , all rats were returned to Context B for the reinstatement session. Rats in the reinstatement groups received three unsignaled foot shocks; rats in the no-reinstatement groups received no foot shocks but remained in the chambers for an identical period. On day 7, all rats were again returned to Context B to probe CSelicited fear during the post-reinstatement test. Data for the postextinction and post-reinstatement tests represent mean freezing for the first three test CS presentations.

\section{Data analysis}

Defensive freezing, defined as the absence of all nonrespiratory movement (Blanchard and Blanchard 1971; Fanselow 1980), served as the index of fear in all rat experiments. Freezing was manually scored from videotapes/DVDs following behavioral testing, and time spent freezing for each 30-sec CS was converted to a freezing percentage. Behavioral scorers were blind to group specification. Data in graphs represent group means \pm SEM. Since all immediate and delayed extinction groups in both experiments were treated identically up to the end of the extinction sessions, data for all animals within each condition were combined for statistical analysis of acquisition learning and withinsession extinction learning (Fig. 4). Statistical analysis was conducted with GraphPad Prism (version 4.0). Experimental phases with only two groups and a single measure were analyzed with unpaired two-tailed $t$-tests. Time course data were analyzed using two-way (group $\times$ time) ANOVAs with planned post-hoc Bonferroni tests to compare group differences at individual time points. Differences were considered significant when $P<0.05$.

\section{Spontaneous recovery experiment}

Subjects, apparatus, and data analysis

These were the same as the reinstatement experiment with one exception. Grid floors in Context B were covered with black Plexiglas inserts for all experimental phases conducted in B.

Procedure

The spontaneous recovery experiment consisted of three phases: acquisition, extinction, and spontaneous recovery test. Acquisition was conducted in Context A and the extinction and spontaneous recovery test phases were conducted in Context B. Immediate and delayed extinction conditions were compared (8 rats/group), as previously. Acquisition and extinction sessions were identical to those reported for the reinstatement experiment. Following three CSUS pairings in A, rats received 20 nonreinforced CS presentation in Context B either 12 min or $3 \mathrm{~d}$ following acquisition. The spontaneous recovery test was conducted $21 \mathrm{~d}$ after the extinction session for both groups and was identical to the tests of the reinstatement experiment (five nonreinforced CS presentations in B).

\section{Acknowledgments}

This work was supported by a Fulbright award to D.S.; NRSA F32 MH077458 grant to C.K.C.; NIH grants R01 MH46516, R37 MH38774, K05 MH067048, P50 MH58911 to J.E.L.; and a James S. McDonnell Foundation and NIH R21 MH072279 grants to E.A.P. The authors thank Rita Jou for technical support and assistance in running the experiments and Leib Litman for assistance with statistical analysis.

\section{References}

Alvarez, R.P., Johnson, L., and Grillon, C. 2007. Contextual-specificity of short-delay extinction in humans: Renewal of fear-potentiated startle in a virtual environment. Learn. Mem. 14: 247-253.

Baum, M. 1988. Spontaneous recovery from the effects of flooding (exposure) in animals. Behav. Res. Ther. 26: 185-186.

Bisson, J.I., Jenkins, P.L., Alexander, J., and Bannister, C. 1997. Randomised controlled trial of psychological debriefing for victims of acute burn trauma. Br. J. Psychiatry 171: 78-81.

Blanchard, R.J. and Blanchard, D.C. 1971. Defensive reactions in the albino rat. Learn. Motiv. 2: 351-362.

Bouton, M.E. 1984. Differential control by context in the inflation and reinstatement paradigms. J. Ex. Psychol. Anim. Behav. Process. 10: $56-74$.

Bouton, M.E. and Bolles, R.C. 1979a. Role of conditioned contextual stimuli in reinstatement of extinguished fear. J. Exp. Psychol. Anim. Behav. Process. 5: 368-378.

Bouton, M.E. and Bolles, R.C. 1979b. Contextual control of the extinction of conditioned fear. Learn. Motiv. 10: 445-466.

Bouton, M.E. and King, D.A. 1983. Contextual control of the extinction of conditioned fear: Tests for the associative value of the context. $J$. Exp. Psychol. Anim. Behav. Process. 9: 248-265.

Bouton, M.E. and King, D.A. 1986. Effect of context on performance to conditioned stimuli with mixed histories of reinforcement and 
nonreinforcement. J. Ex. Psychol. Anim. Behav. Process. 12: 4-15.

Bouton, M.E. and Peck, C.A. 1989. Context effects on conditioning, extinction, and reinstatement in an appetitive conditioning preparation. Anim. Learn. Behav. 17: 188-198.

Cain, C.K., Godsil, B.P., Jami, S., and Barad, M. 2005. The L-type calcium channel blocker nifedipine impairs extinction, but not reduced contingency effects, in mice. Learn. Mem. 12: 277-284.

Campfield, K.M. and Hills, A.M. 2001. Effect of timing of critical incident stress debriefing (CISD) on posttraumatic symptoms. J. Trauma. Stress 14: 327-340.

Craske, M.G. 1999. Anxiety disorders: Psychological approaches to theory and treatment. Westview Press, Boulder, CO.

Critchley, H.D., Mathias, C.J., and Dolan, R.J. 2002. Fear conditioning in humans: The influence of awareness and autonomic arousal on functional neuroanatomy. Neuron 33: 653-663.

Davis, M. and Whalen, P.J. 2001. Vigilance and emotion. Mol. Psychiatry 6: $13-34$.

Dirikx, T., Hermans, D., Vansteenwegen, D., Baeyens, F., and Eelen, P. 2007. Reinstatement of conditioned responses in human differential fear conditioning. J. Behav. Ther. Exp. Psychiatry 38: 237-251.

Everly Jr., G.S. and Mitchell, J.T. 1999. Critical incident stress management (CISM): A new era and standard of care in crisis intervention, 2nd ed. Chevron Publishing, Ellicott City, MD.

Eysenck, H.J. 1968. A theory of the incubation of anxiety/fear responses. Behav. Res. Ther. 6: 309-321.

Fanselow, M.S. 1980. Conditioned and unconditional components of post-shock freezing. Pavlov. J. Biol. Sci. 15: 177-182.

Fendt, M. and Fanselow, M.S. 1999. The neuroanatomical and neurochemical basis of conditioned fear. Neurosci. Biobehav. Rev. 23: 743-760.

Frohardt, R.J., Guarraci, F.A., and Bouton, M.E. 2000. The effects of neurotoxic hippocampal lesions on two effects of context after fear extinction. Behav. Neurosci. 114: 227-240.

Gray, M.J. and Litz, B.T. 2005. Behavioral interventions for recent trauma: Empirically informed practice guidelines. Behav. Modif. 29: $189-215$.

Hermans, D., Dirikx, T., Vansteenwegen, D., Baeyens, F., Van den Bergh, O., and Eelen, P. 2005. Reinstatement of fear responses in human aversive conditioning. Behav. Res. Ther. 43: 533-551.

Jacobs, W.J. and Nadel, L. 1985. Stress-induced recovery of fears and phobias. Psychol. Rev. 92: 512-531.

Kalisch, R., Korenfeld, E., Stephan, K.E., Weiskopf, N., Seymour, B., and Dolan, R.J. 2006. Context-dependent human extinction memory is mediated by a ventromedial prefrontal and hippocampal network. $J$. Neurosci. 26: 9503-9511.

LaBar, K.S. and Phelps, E.A. 2005. Reinstatement of conditioned fear in humans is context dependent and impaired in amnesia. Behav. Neurosci. 119: 677-686.

LaBar, K.S., Gatenby, J.C., Gore, J.C., LeDoux, J.E., and Phelps, E.A. 1998. Human amygdala activation during conditioned fear acquisition and extinction: A mixed-trial fMRI study. Neuron 20: $937-945$.

LeDoux, J.E. 2000. Emotion circuits in the brain. Annu. Rev. Neurosci. 23: $155-184$

Lin, C.-H., Yeh, S.-H., Lu, H.-Y., and Gean, P.-W. 2003a. The similarities and diversities of signal pathways leading to consolidation of conditioning and consolidation of extinction of fear memory. $J$. Neurosci. 23: 8310-8317.

Lin, C.-H., Yeh, S.-H., Leu, T.-H., Chang, W.-C., Wang, S.-T., and Gean, P.-W. 2003b. Identification of calcineurin as a key signal in the extinction of fear memory. J. Neurosci. 23: 1574-1579.

Maren, S. and Chang, C.-H. 2006. Recent fear is resistant to extinction. Proc. Natl. Acad. Sci. 103: 18020-18025.

Maren, S. and Quirk, G.J. 2004. Neuronal signalling of fear memory. Nat. Rev. Neuro. 5: 844-852.

McNally, R.J., Bryant, R.A., and Ehlers, A. 2003. Does early psychological intervention promote recovery from posttraumatic stress? Psychol. Sci. Public Interest 4: 45-79.

Milad, M.R., Quinn, B.T., Pitman, R.K., Orr, S.P., Fischl, B., and Rauch, S.L. 2005. Thickness of ventromedial prefrontal cortex in humans is correlated with extinction memory. Proc. Natl. Acad. Sci. 102: $10706-10711$.

Milad, M.R., Wright, C.I., Orr, S.P., Pitman, R.K., Quirk, G.J., and Rauch, S.L. 2007. Recall of fear extinction in humans activates the ventromedial prefrontal cortex and hippocampus in concert. Biol. Psychiatry 62: 446-454.

Morris, J.S., Ohman, A., and Dolan, R.J. 1998. Conscious and unconscious emotional learning in the human amygdala. Nature 393: 467-470.

Myers, K.M. and Davis, M. 2002. Behavioral and neural analysis of extinction. Neuron 36: 567-584.

Myers, K.M., Ressler, K.J., and Davis, M. 2006. Different mechanisms of fear extinction dependent on length of time since fear acquisition. Learn. Mem. 13: 216-223.

Ohman, A. 2005. The role of the amygdala in human fear: Automatic detection of threat. Psychoneuroendocrinology 30: 953-958.

Olsson, A., Ebert, J.P., Banaji, M.R., and Phelps, E.A. 2005. The role of social groups in the persistence of learned fear. Science 309: 785-787.

Pavlov, I.P. 1927. Conditioned reflexes (G.V. Anrep, Trans.). Oxford University Press, London, UK.

Phelps, E.A., Delgado, M.R., Nearing, K.I., and LeDoux, J.E. 2004. Extinction learning in humans: Role of the amygdala and vmPFC. Neuron 43: 897-905.

Quirk, G.J. 2002. Memory for extinction of conditioned fear is long-lasting and persists following spontaneous recovery. Learn. Mem. 9: 402-407.

Quirk, G.J. and Gehlert, D.R. 2003. Inhibition of the amygdala: Key to pathological states? Ann. N. Y. Acad. Sci. 985: 263-272.

Quirk, G.J., Russo, G.K., Barron, J.L., and Lebron, K. 2000. The role of ventromedial prefrontal cortex in the recovery of extinguished fear. J. Neurosci. 20: 6225-6231.

Rauch, S.L., Shin, L.M., and Phelps, E.A. 2006. Neurocircuitry models of posttraumatic stress disorder and extinction: Human neuroimaging research-Past, present, and future. Biol. Psychiatry 60: 376-382.

Rescorla, R.A. 2004. Spontaneous recovery. Learn. Mem. 11: 501-509.

Rescorla, R.A. and Heth, C.D. 1975. Reinstatement of fear to an extinguished conditioned stimulus. J. Exp. Psychol. Anim. Behav. Process. 1: 88-96.

Rothbaum, B.O. and Davis, M. 2003. Applying learning principles to the treatment of post-trauma reactions. Ann. N. Y. Acad. Sci. 1008: 112-121.

Wagner, A.R. 1978. Expectancies and the priming of STM. In Cognitive processes in animal behavior (eds. S.H. Hulse, H. Fowler, and W.K. Honig), pp. 177-209. Erlbaum, Hillsdale, NJ.

Wagner, A.R. 1981. SOP: A model of automatic memory processing in animal behavior. In Information processing in animals: Memory mechanisms (eds. N.E. Spear and R.R. Miller), pp. 5-47. Erlbaum, Hillsdale, NJ.

Wagner, A.R. and Brandon, S.E. 1989. Evolution of a structured connectionist model of Pavlovian conditioning (AESOP). In Contemporary Learning Theories: Pavlovian Conditioning and the Status of Traditional Learning Theory (eds. S.B. Klein and R.R. Mowrer), pp. 149-189. Erlbaum, Hillsdale, NJ.

Westbrook, R.F., Iordanova, M., McNally, G., Richardson, R., and Harris, J.A. 2002. Reinstatement of fear to an extinguished conditioned stimulus: Two roles for context. J. Exp. Psychol. Anim. Behav. Process. 28: 97-110.

Wolpe, J. 1969. The practice of behavior therapy. Pergamon, New York.

Received January 15, 2008; accepted in revised form March 31, 2008. 


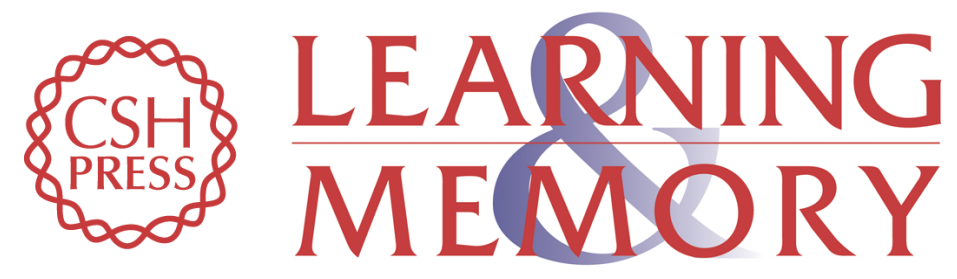

\section{Evidence for recovery of fear following immediate extinction in rats and humans}

Daniela Schiller, Christopher K. Cain, Nina G. Curley, et al.

Learn. Mem. 2008, 15:

Access the most recent version at doi:10.1101//m.909208

References This article cites 47 articles, 13 of which can be accessed free at:

http://learnmem.cshlp.org/content/15/6/394.full.html\#ref-list-1

License

Email Alerting Receive free email alerts when new articles cite this article - sign up in the box at the Service top right corner of the article or click here. 